\title{
Análise de Publicaçốes Relacionando Altas Habilidades/ Superdotação, Criatividade e Bilinguismo nas Bases de Dados Scielo, SCOPUS E WEB OF SCIENCE Analysis of Publications ReLATING GIFTEDNESS, CREATIVITY AND BILINGUALISM IN THE SCIELO, SCOPUS AND WEB OF SCIENCE DATABASES
}

\author{
Taís Crema Remoli FERREIRA ${ }^{2}$ \\ Miguel Claudio Moriel CHACON ${ }^{3}$ \\ Vera Lucia Messias Fialho CAPELLINI ${ }^{4}$
}

\begin{abstract}
RESUMO: Neste artigo, propôs-se a realizar uma busca em uma base de dados nacional (SciELO) e em duas internacionais (Scopus e Web of Science) a fim de investigar possíveis conexões entre os temas altas habilidades/superdotação (AH/SD), criatividade e bilinguismo, uma vez que o interesse pelos três unitermos vêm crescendo. Na verificação realizada em 2020, a partir de diferentes combinaçôes desses unitermos, tanto em Língua Portuguesa como Inglesa, nenhum trabalho que relacionava os três tópicos foi encontrado, mas obtiveram-se dez artigos que abordavam a conexão entre dois deles. A conexão entre AH/SD e bilinguismo foi a temática mais recorrente, com seis estudos. A maior parte desses achados investigou a forma de avaliar e trabalhar com alunos com AH/SD bilíngues inseridos em diferentes realidades, havendo a crítica dos autores às avaliaçóes e aos testes padronizados que não se preocupavam em englobar diferenças culturais e linguísticas nesses instrumentos. Os quatro outros artigos abordaram criatividade e bilinguismo, tendo como foco a comparação de diferentes medidas de criatividade entre crianças bilíngues e monolíngues. Por meio dos dados obtidos nos textos, houve ganho mais significativo em diferentes medidas de criatividade às crianças bilíngues. A partir da análise dos achados, verificou-se a pouca produçâo relacionando as temáticas apresentadas, mesmo limitando-se a busca à conexão de apenas dois dos unitermos citados. Assim, sugerem-se novos estudos em ambientes bilíngues com foco em estudantes público-alvo da Educaçáo Especial, especificamente aqueles com AH/SD. Recomenda-se, também, o desenvolvimento da criatividade nesse contexto e a divulgação de mais pesquisas empíricas para que novos trabalhos possam ser replicados.
\end{abstract}

PALAVRAS-CHAVE: Educação Especial. Altas habilidades/Superdotação. Criatividade. Bilinguismo. Revisão de literatura.

\begin{abstract}
In this article, it was proposed to conduct a search in a national database (SciELO) and in two international ones (Scopus and Web of Science), in order to investigate possible connections between the themes giftedness, creativity and bilingualism, as interest in the three terms has been growing. In the verification carried out in 2020 with different combinations of these uniterms, written in Portuguese and English, no work related to the three topics was found, but ten articles addressing the connection between two of the topics were obtained. The connection between giftedness and bilingualism was the most recurrent theme, with six studies. Most of them investigated how to evaluate and work with gifted bilingual students inserted in different realities with the authors' criticism of the standardized evaluations and tests that were not concerned with encompassing cultural and linguistic differences in these instruments. The four other articles addressed creativity and bilingualism and were focused on comparing different measures of creativity of bilingual and monolingual children. Through the data obtained in the texts, there was a more significant gain in different measures of creativity for bilingual children. From the analysis of the findings, there was little production related to the themes presented, even though the search was limited to the connection of only two of the aforementioned uniterms. Thus, new studies are suggested in bilingual environments with a focus on target students of Special Education, specifically those with giftedness. It is also recommended the development of creativity in this context and the dissemination of more empirical research so that new works can be replicated.
\end{abstract}

KEYWORDS: Special Education. Giftedness. Creativity. Bilingualism. Literature review.

\footnotetext{
${ }^{1}$ https://doi.org/10.1590/1980-54702021v27e0030

${ }^{2}$ Doutora em Educação pela Universidade Estadual Paulista - UNESP. Marília / São Paulo / Brasil. E-mail: tais.remoli@gmail. com. ORCID: https://orcid.org/0000-0001-5279-7718

${ }^{3}$ Docente. Departamento de Educação Especial da UNESP. Pós-Graduação em Educação. Marília / São Paulo / Brasil. E-mail: psi@miguelchacon.com.br. ORCID: https://orcid.org/0000-0002-6473-8958

${ }^{4}$ Docente. Universidade Estadual Paulista - UNESP. Bauru / São Paulo/ Brasil. E-mail: vera.capellini@unesp.br. ORCID: https:// orcid.org/0000-0002-9184-8319
} 


\section{INTRODUÇÁo}

O tema Altas Habilidades/Superdotação $(\mathrm{AH} / \mathrm{SD})^{5}$ vem despertando o interesse de pesquisadores em diversas partes do mundo e diferentes concepçóes costumam ser utilizadas, como: "a criança superdotada extrapola os limites do ensino que lhe é ofertado, sua imaginação é frutífera e aguçada" (Piske et al., 2016, p. 207). Além disso, alunos com AH/SD destacam-se em raciocínio verbal e vocabulário superior à idade, nível de leitura acima da média do grupo, habilidades de comunicação e linguagem criativa (Secretaria de Educação Especial \& Ministério da Educação, 2006).

A fim de compreender a possível conexão entre as AH/SD e o ensino de línguas, Biedrón e Pawlak (2012) realizaram a avaliação de crianças polonesas utilizando a Wechsler Intelligence Scale e o Modern Language Aptitude Test. Verificou-se que os alunos com AH/SD e falantes de uma segunda língua apresentaram maior inteligência que a média da população da Polônia, bem como que inteligência e segunda língua se correlacionaram moderadamente. Tal resultado é condizente com as informaçóes do guia Identifying Gifted and Talented English Language Learners (State Board of Education - State of Iowa, 2008), segundo o qual crianças com AH/SD adquirem uma segunda língua mais rapidamente. Baser e Kanar (2014) confirmaram essa afirmação destacando, especialmente, os indivíduos com habilidades linguísticas avançadas, pois possuem compreensão antecipada, elaboração de perguntas incomuns e de sentenças mais longas. Por isso, reforça-se a importância de familiares e de professores estarem atentos a esse público, frequentemente negligenciado no ensino de um segundo idioma (Biedrón \& Pawlak, 2016).

Além da conexão entre AH/SD e aquisição de segunda língua, AH/SD e criatividade também têm algo em comum: são processos essencialmente humanos (Ribeiro \& Galvão, 2018). De acordo com Bahia (2016), para avaliar a criatividade de estudantes com AH/SD, é importante incluir o uso de instrumentos variados, como testes, escalas, observaçóes, avaliação de processos e de produtos, a fim de obter-se o maior número de informaçóes possíveis. Com esse intuito, Gonçalves (2010) utilizou dois instrumentos, Matrizes Progressivas de Raven Escala Geral e Teste Torrance de Pensamento Criativo, tendo 48 alunos de $6^{\circ}$ ano do Ensino Fundamental como sujeitos da pesquisa. Como resultado, foram obtidos maiores escores nos fatores originalidade verbal e figurativa no grupo de alunos com AH/SD.

Ao realizar uma revisão de literatura de artigos publicados de 2005 a 2015 que abordavam a conexão entre criatividade e AH/SD, Remoli e Capellini (2017) obtiveram 20 artigos com algum tipo de relação entre os termos. As autoras os classificaram em estudos experimentais (12), estudos teóricos (4) e revisão de literatura (4). $\mathrm{Na}$ análise dos resultados, houve o predomínio de temáticas relacionadas à comparação da criatividade em alunos com e sem AH/SD, com foco em medir e comparar a criatividade. No entanto, não foram encontrados estudos empíricos que abordassem programas de desenvolvimento da criatividade de pessoas com AH/SD.

Quanto à criatividade e ao bilinguismo, há indicadores da diferença da criatividade entre indivíduos bilíngues e monolíngues. Hamers e Blanc (2004), ao descreverem uma pesquisa realizada com crianças na Nigéria e no País de Gales, destacaram que as bilíngues, de

${ }^{5}$ Neste trabalho, optou-se por empregar a terminologia "altas habilidades/superdotaçâo", abreviada pela sigla AH/SD, utilizada na Política Nacional de Educação Especial. 
ambos os países, apresentaram maiores escores em pensamento divergente e criatividade que as monolíngues. A relação entre criatividade e ensino de línguas também foi comprovada por Lee e Kim (2011) por meio da avaliação de 114 estudantes bilíngues (coreano/inglês) com o Teste Torrance de Pensamento Criativo. Os resultados indicaram que o grau de bilinguismo se correlacionava positivamente com a criatividade independentemente de sexo ou idade.

Nota-se, por meio das pesquisas descritas, o interesse de diferentes autores pela relação entre AH/SD, criatividade e bilinguismo. Por isso, este artigo tem como objetivo apresentar os resultados obtidos a partir de pesquisa sobre esses construtos em três bases de dados.

\section{Desenvolvimento}

Com o intuito de conhecer mais as possíveis conexões entre altas AH/SD, criatividade e bilinguismo, realizou-se uma pesquisa bibliográfica. Foram consultadas uma base de dados nacional, a Scientific Electronic Library Online (SciELO), e duas internacionais, Scopus e Web of Science. Os resultados encontrados em março de 2020 estão tabulados e apresentados neste trabalho. A fim de obter-se um maior número de artigos relacionados à temática em questáo, foram utilizadas diferentes combinações de unitermos (indicadas na Tabela 1). Como critério de inclusão nessa primeira etapa do trabalho, os descritores mencionados deveriam estar presentes no resumo, nas palavras-chave ou no título. Destaca-se que a busca náo se concentrou em nenhum limitador quanto ao período em que as produçóes foram publicadas para que fosse possível encontrar todas as publicaçóes dessas temáticas. A quantidade de itens, a partir de cada combinação, está apresentada na Tabela 1 .

\section{Tabela 1}

Quantidade de artigos obtidos nas bases de dados SciELO, Scopus e Web of Science em 2020 por meio do cruzamento de diferentes descritores

\begin{tabular}{l|c|c}
\hline \multicolumn{1}{c|}{ Descritores utilizados $^{\mathbf{6}}$} & Base de dados & Quantidade encontrada \\
\hline criatividade; superdotação; bilinguismo & SciELO & 0 \\
\hline criatividade; superdotação; bilíngue & SciELO & 0 \\
\hline criatividade; altas habilidades; bilinguismo & SciELO & 0 \\
\hline criatividade; altas habilidades; bilíngue & SciELO & 0 \\
\hline criatividade; bilinguismo & SciELO & 0 \\
\hline bilinguismo; altas habilidades & SciELO & 0 \\
\hline bilinguismo; superdotação & SciELO & 0 \\
\hline creativity; giftedness; bilingualism & Scopus & 1 \\
\hline creativity; high ability; bilingual & Scopus & 6 \\
\hline creative; giftedness; bilingualism & Scopus & \\
\hline
\end{tabular}

\footnotetext{
${ }^{6}$ Visto que há diferentes pesquisas na literatura voltadas a investigar a relação entre AH/SD e criatividade, como descreveram Remoli e Capellini (2017) - especialmente devido à fundamentação na Teoria dos Três Anéis, de Renzulli e Reis (1997), que conecta os traços de AH/SD, criatividade e compromisso com a tarefa - optou-se por não utilizar o cruzamento entre apenas esses dois unitermos nesta busca, que tem como foco principal a conexão de três construtos, bem como de apresentar informações novas entre tais relações.
} 


\begin{tabular}{l|c|c}
\hline giftedness; bilingualism & Scopus & 29 \\
\hline creativity; giftedness; bilingualism & Web of Science & 0 \\
\hline creativity; giftedness, bilingual & Web of Science & 0 \\
\hline creativity; high ability; bilingualism & Web of Science & 5 \\
\hline giftedness; bilingualism & Web of Science & 0 \\
\hline giftedness; bilingual & Web of Science & 2 \\
\hline high ability; bilingual & Web of Science & 6 \\
\hline Total das três bases de dados & & 51 \\
\hline
\end{tabular}

Observa-se que foram encontrados 51 itens a partir dos diferentes descritores selecionados, sendo 36 deles da Scopus, 13 da Web of Science e dois da SciELO. Visto que o objetivo deste estudo é apresentar os entrelaces entre os construtos selecionados - AH/SD, criatividade e bilinguismo -, na segunda etapa da verificação, realizou-se a leitura de todos os resumos. Apenas os artigos que apresentaram conexóes, ao menos entre dois dos descritores mencionados na Tabela 1 , foram incluídos de forma mais detalhada neste trabalho, sendo cinco da Scopus, cinco da Web of Science e um da SciELO. Destaca-se que, ao todo, foram encontrados dez artigos, dado que um deles, Yang et al. (2018), foi obtido de forma duplicada nas duas primeiras bases. Os resultados são apresentados no Quadro 1 e descritos a seguir.

\section{Quadro 1}

Artigos obtidos nas bases de dados SciELO, Scopus e Web of Science em 2020 com relação entre pelo menos dois dos descritores (AH/SD, criatividade e bilinguismo)

\begin{tabular}{|l|l|l|l|l|}
\hline Data & \multicolumn{1}{|c|}{ Autoria } & \multicolumn{1}{|c|}{ Local } & \multicolumn{1}{|c|}{ Foco do estudo e participantes } & Base de dados \\
\hline 1994 & Palaniappan, A. K. & Malásia & $\begin{array}{l}\text { Análise de teste de AH/SD com versão } \\
\text { bilíngue para estudantes da Malásia. }\end{array}$ & Web of Science \\
\hline 1995 & $\begin{array}{l}\text { Kitano, M. K., \& } \\
\text { Espinosa, R. }\end{array}$ & EUA & $\begin{array}{l}\text { Identificação e atendimento de estudantes } \\
\text { americanos bilíngues com AH/SD. }\end{array}$ & Web of Science \\
\hline 2098 & Strand, S. & Inglaterra & $\begin{array}{l}\text { Averiguação de desempenho escolar de dife- } \\
\text { rentes públicos, como estudantes com AH/ } \\
\text { SD e bilíngues, no Reino Unido. }\end{array}$ & Web of Science \\
\hline 2006 & Gonzalez, V. & EUA & $\begin{array}{l}\text { Avaliação da criatividade de adolescentes e } \\
\text { adultos bilíngues e monolíngues. }\end{array}$ & SciELO \\
\hline 2008 & Brice, A. E. et al. & EUA & $\begin{array}{l}\text { Avaliação da segunda língua de crianças } \\
\text { hispânicas com AH/SD. }\end{array}$ & Scopus \\
\hline 2009 & Aust, K. et al. & Alemandimento a estudantes bilíngues com & Scopus \\
\hline
\end{tabular}




\begin{tabular}{|l|l|l|l|l|}
\hline 2012 & Leikin, M. & Israel & $\begin{array}{l}\text { Verificação da criatividade de crianças bilín- } \\
\text { gues e monolíngues. }\end{array}$ & Scopus \\
\hline 2014 & $\begin{array}{l}\text { Leikin, M., \& } \\
\text { Tovli, E. }\end{array}$ & Israel & $\begin{array}{l}\text { Análise da criatividade de crianças bilíngues } \\
\text { e monolíngues. }\end{array}$ & Scopus \\
\hline 2018 & Yang, Z. et al. & China & $\begin{array}{l}\text { Avaliação da criatividade de estudantes de } \\
\text { curso bilíngue de enfermagem. }\end{array}$ & $\begin{array}{l}\text { Scopus e } \\
\text { Web of Science }\end{array}$ \\
\hline
\end{tabular}

De acordo com os achados, as publicações foram realizadas entre 1994 e 2018, sendo os Estados Unidos da América (EUA) o país com maior número (3), seguido por Israel (2). Outros cinco países tiveram uma publicação cada: Alemanha, Brasil, China, Inglaterra e Malásia. Quanto à temática, seis textos abordaram a relação entre pessoas com AH/SD e bilinguismo e quatro deles tiveram como foco a avaliação da criatividade de pessoas bilíngues. A seguir, são descritos os artigos a partir de duas categorias. Ressalta-se que, embora tenha havido diferentes combinaçóes de unitermos, não foram encontrados textos que abordassem a relação entre $\mathrm{AH} / \mathrm{SD}$, criatividade e bilinguismo simultaneamente.

\subsection{ARTIGOS QUE APRESENTARAM CONEXÁO ENTRE AH/SD E BILINGUISMO}

O primeiro artigo obtido nesta busca foi o de Palaniappan (1994), que analisou a versão bilíngue do Khatena-Morse Multitalent Perception Inventory, formas A e B. O teste é composto por 50 itens para escolhas entre duas alternativas. $\mathrm{O}$ instrumento foi testado e retestado em estudantes da Malásia, sendo considerado adequado para avaliar a percepção de $\mathrm{AH} /$ $\mathrm{SD}$ em várias áreas de talento. É recomendado que o estudo seja replicado com outros grupos a fim de confirmarem-se os resultados.

Kitano e Espinosa (1995) também pesquisaram sobre AH/SD, focando-se no desafio de atender a alunos com AH/SD em outros contextos culturais devido à dificuldade linguística. De acordo com os autores, nos EUA, além de alunos bilíngues espanhol-inglês, que eram a maioria à época, havia também outros 100 grupos linguísticos diferentes. Por isso, a partir de sua revisão de literatura, os autores ressaltaram que os educadores precisam de procedimentos apropriados para identificação e prestação de serviço a esse público, com o propósito de atender a alunos com AH/SD de origens culturais não convencionais, pensando-se também na complexidade da diversidade linguística.

O artigo de Strand (1998) teve como objetivo analisar o desempenho nas avaliaçóes escolares, cujos resultados haviam sido publicados pelo governo britânico. Tais dados foram criticados por apresentarem uma média que não refletia as especificidades dos estudantes, como aqueles com AH/SD, devido à apresentação dos resultados brutos das escolas ou pelo agrupamento dos dados de diferentes disciplinas. Após realizar análises diversificadas, sem agrupar sujeitos, o autor verificou que alunos com algum tipo de necessidade educacional especial ou alunos bilíngues, que precisam de suporte em Língua Inglesa (como os de origem caribenha), obtiveram resultados mais baixos na avaliação do que seria esperado para sua capacidade de raciocínio, tecendo uma crítica a esse tipo de avaliação padronizada. 
O primeiro trabalho publicado após os anos 2000 foi o de Gonzalez (2006). Esse estudo quase-experimental com alunos hispânicos nos EUA verificou o efeito de fatores socioeconômicos - Socialeconomic Effect Status (SES) - e de aprendizado linguístico e cultural em crianças com AH/SD, buscando-se uma alternativa às escalas de desenvolvimento de habilidades cognitivas empregadas até então. Os resultados mostraram o efeito da aprendizagem de línguas e dos fatores linguísticos e culturais, com continuidades e descontinuidades nessa nova forma de verificação. Assim, foram sugeridas avaliaçóes mais apropriadas e que considerassem, além das questóes cognitivas das AH/SD, os fatores linguísticos e culturais em novas avaliações.

Realizada no mesmo período, a pesquisa de Brice et al. (2008) apresentou preocupaçóes semelhantes. Os autores ressaltaram um aumento na quantidade de latinos, tendo o espanhol como primeira língua, nos Estados Unidos, considerado um desafio para os educadores locais. O objetivo do estudo, realizado com alunos do Middle School (equivalente ao Ensino Fundamental II), foi comparar o discurso dos participantes de programas para AH/SD e de programas regulares de ensino. Como resultados, obteve-se pequenas vantagens linguísticas para os alunos no programa para AH/SD; no entanto, a conclusão da pesquisa indicou que bilinguismo, habilidades linguísticas e AH/SD envolvem muitas variáveis e que sua relação não é, necessariamente, direta.

Também investigando as diferentes formas de atendimento, os pesquisadores alemães Aust et al. (2009) realizaram um estudo longitudinal para verificar se estudantes matriculados em escolas classificadas como abrangentes, padronizadas, voltadas à Matemática e às Ciências ou com perfil bilíngue ${ }^{7}$ realizariam trajetórias diversas no desenvolvimento das habilidades de autoconceito geral e no domínio específico de autoconceito em Matemática e Língua Alemã após a transição para o Ensino Secundário, no $5^{\circ}$ ano $^{8}$. Os resultados relatados foram que as crianças das salas de AH/SD tiveram uma diminuição na habilidade de autoconceito geral, mas não em autoconceito em Matemática ou na Língua Alemã. Destaca-se que não se encontrou no texto mais informações quanto à conexão entre alunos com AH/SD e escolas com perfil bilíngue.

Ao analisar a temática dos seis estudos, nota-se que três artigos se preocuparam com a avaliação apropriada de crianças bilíngues com AH/SD - mesma temática do estudo de Biedrón e Pawlak (2012). Os textos citaram a avaliação por meio de uma versão bilíngue para verificação de AH/SD em várias áreas de talento (Palaniappan, 1994), bem como sugeriram alternativa às escalas de desenvolvimento de habilidades cognitivas para crianças com AH/SD (Gonzalez, 2006) e interpretação de maneira individualizada do resultado de avaliaçóes padronizadas (Strand, 1998).

$\mathrm{O}$ artigo de Strand (1998) teceu ainda uma crítica à maneira de avaliarem-se sujeitos diferentes e com características distintas de forma igual e padronizada, o que remete à afirmação de negligência de crianças com AH/SD e falantes de um segundo idioma (Biedrón \& Pawlak, 2016), especialmente quando sua língua é utilizada pela minoria e pouco valorizada. Ademais, observou-se a presença de diferenças culturais e linguísticas não contempladas nos diferentes testes empregados.

\footnotetext{
${ }^{7}$ Traduçâo livre da terminologia empregada pelos autores: "comprehensive school, standard Gymnasium classes, Gymnasium classes with a mathematics/science or bilingual profile".

${ }^{8}$ Transição do Ensino Fundamental I para o Ensino Fundamental II.
} 
Desse modo, sugere-se atenção a esse público, a fim de que se possa ter condiçóes de mostrar sua habilidade de raciocínio verbal, leitura, comunicação e linguagem criativa (Secretaria de Educação Especial \& Ministério da Educação, 2006), bem como sua inteligência (Biedrón \& Pawlak, 2012). Os outros três artigos da busca relacionam-se a essa mesma temática. Kitano e Espinosa (1995) ressaltaram a importância da identificação e da prestação de serviço a alunos com AH/SD de origens culturais não convencionais, considerando-se também sua diversidade linguística. Brice et al. (2008) descreveram as vantagens de crianças com AH/SD que estavam em um programa voltado a alunos bilíngues com AH/SD, e Aust et al. (2009) investigaram longitudinalmente as crianças com AH/SD inseridas em diferentes tipos de escola.

Iniciativas como essas são importantes para que tal público tenha opções de identificação e atendimento, a fim de desenvolver plenamente suas potencialidades. Afinal, de acordo com Renzulli (2018), o papel da educação para pessoas com AH/SD é proporcionar o máximo de oportunidades para autorrealização e expressão nas áreas de desempenho, ampliando-se o número de pessoas na sociedade que possam auxiliar na resoluçáo de problemas contemporâneos. Nesse sentido, pessoas bilíngues podem ter vantagens em relação ao pensamento criativo e desenvolver maior sensibilidade comunicativa (Wei, 2000), favorecendo tal processo.

\subsection{ARTIGOS QUE APRESENTARAM CONEXÃO ENTRE CRIATIVIDADE E BILINGUISMO}

Mendonça e Fleith (2005) são as autoras do único artigo brasileiro obtido na busca. Elas avaliaram a criatividade, a inteligência e o autoconceito em adolescentes e adultos bilíngues e monolíngues, entre 14 e 57 anos, por meio dos instrumentos: Teste Torrance de Pensamento Criativo (TTCT), Teste Não-Verbal de Raciocínio para Adultos (TNVRA) e Escala Fatorial de Autoconceito (EFA). Como resultados, Mendonça e Fleith (2005) relataram que os indivíduos bilíngues apresentaram escores superiores nas medidas de criatividade verbal e figurativa e de inteligência quando comparados aos monolíngues. As pesquisadoras também encontraram correlação positiva entre criatividade e autoconceito para estudantes bilíngues.

Já Leikin (2012), em suas pesquisas, trabalhou com três grupos de crianças: bilíngues de uma pré-escola bilíngue (russo e hebraico), bilíngues de uma pré-escola monolíngue (hebraico) e monolíngues de uma de uma pré-escola monolíngue (hebraico). Os participantes realizaram o Picture multiple solution task, de criatividade geral, e o Creating equal number task, de criatividade matemática. Como resultados, tanto o bilinguismo precoce quanto alguma forma de educação bilíngue influenciaram a criatividade geral e a matemática das crianças. As diferenças entre crianças bilíngues da pré-escola e crianças monolíngues foram mais proeminentes (em favor dos bilíngues), confirmando a hipótese sobre as diferenças entre habilidades criativas no contexto do desenvolvimento bilíngue e monolíngue.

Leikin e Tovli (2014) também pesquisaram a criatividade dos pré-escolares. Os participantes foram divididos nos grupos: bilíngues (russo e hebraico) e monolíngues (hebraico). Todos realizaram as mesmas tarefas: Working memory test, Verbal fuency test, Pictorial multiple solution task on general creativity e Creating equal number task on mathematical creativity. Como resultados, obteve-se efeito positivo do bilinguismo no desenvolvimento da criatividade quanto à resolução de problemas, observando melhor desempenho dos bilíngues em duas das três tare- 
fas de criatividade linguística, bem como maior produtividade nas medidas criativas e melhor performance na criatividade matemática.

A pesquisa mais recente, de Yang et al. (2018), foi realizada na China com estudantes de Enfermagem de classe bilíngue que se matricularam em uma disciplina facultativa de Inovation and creative thinking. Os participantes preencheram o Creativity and innovation effectiveness profile antes e após a disciplina. Como resultados, obteve-se que os sete domínios de criatividade avaliados (consciência criativa, níveis de curiosidade, habilidades para quebrar padróes, capacidade de nutrir ideias, disposição para experimentar e assumir riscos, coragem e resiliência e persistência energética) foram considerados significativamente mais altos no pós-teste. Dessa maneira, os autores pontuaram que os universitários bilíngues avaliados puderam melhorar sua capacidade de inovar e criar por meio do aprendizado e que a experiência prática forneceu uma boa referência para os professores que desejam que seus alunos sejam criativos e inovadores.

Nesses quatro artigos mencionados nesta seção, o foco foi a verificação e a comparação da criatividade de diferentes formas. Mendonça e Fleith (2005), Leikin (2012) e Leikin e Tovli (2014) aplicaram tarefas e testes a fim de comparar indivíduos bilíngues e monolíngues, obtendo vantagens para os primeiros no que diz respeito à criatividade verbal e figurativa e à inteligência, à criatividade geral e matemática e ao desempenho em tarefas de criatividade linguística. Esses resultados são semelhantes aos obtidos nas pesquisas de Hamers e Blanc (2004) e de Lee e Kim (2011), que também encontraram melhor desempenho na população bilíngue.

A avaliação da criatividade de adultos bilíngues foi realizada por meio de pré e pós-teste por Yang et al. (2018), com resultados considerados significativamente mais altos no pós-teste e indicando possibilidade de desenvolvimento na capacidade de inovar e criar por meio do aprendizado. Esse dado mostra-se fundamental, pois remete à possibilidade de promover-se a criatividade por intermédio do trabalho de educadores, já que ela pode ser treinada e desenvolvida (Nakano, 2015). Assim, é de extrema importância que a família, as instituiçóes escolares e o ambiente de trabalho invistam em condiçóes para que a criatividade possa florescer (Alencar et al., 2015).

De forma igualmente importante, é a divulgação de trabalhos que estejam sendo realizados com esse intuito, para que possam ser replicados, visto que, de acordo com Remoli e Capellini (2017), grande parte das publicaçóes ainda se foca em medir e comparar a criatividade. Foram encontrados poucos estudos empíricos que abordassem programas de desenvolvimento da criatividade de forma semelhante à busca atual, a qual está voltada a compreender o construto da criatividade em pessoas com AH/SD e em ambiente bilíngue.

\subsection{CONEXẤo ENTRE AH/SD, CRIATIVIDADE E BILINGUISMO}

$\mathrm{Na}$ verificação das bases de dados citadas, não foram obtidos artigos que abordassem a criatividade de estudantes bilíngues com AH/SD, demonstrando a pouca produção ou publicação de pesquisas atuais voltadas à conexão dos três temas, embora todos tenham tido crescente interesse e aumento de publicaçóes de forma isolada.

Dentro dessa temática, pode-se destacar os resultados da tese de Ferreira (2020), que pesquisou a criatividade de crianças com e sem AH/SD em ambiente bilíngue. Por meio da 
utilização de medidas qualitativa, Teste de Criatividade Figural Infantil (TCFI), e quantitativa, análise da produção de alunos do Ensino Fundamental I em Língua Inglesa, Língua Portuguesa e Arte, obteve-se como resultados, na pós-intervenção, que o potencial criativo daqueles com indicadores de AH/SD se manteve mais alto, e o potencial criativo dos estudantes sem indicadores de AH/SD apresentou grande progresso, havendo desenvolvimento da criatividade em ambos os grupos em fatores diferentes e em ambiente bilíngue.

Tais resultados confirmam os achados da literatura quanto à conexão entre AH/SD e criatividade, assim como as análises das produçóes das crianças ao longo do ano letivo. O grupo com indicadores de AH/SD mostrou-se mais sensível à intervenção realizada e com maior ganho real em diferentes fatores de criatividade se comparado ao sem indicadores (Ferreira, 2020).

Assim sendo, sugere-se que novas pesquisas em ambiente bilíngue sejam realizadas, a fim de analisar se esse tipo de educação se mantém correlacionado ao desenvolvimento da criatividade, lembrando-se também de considerar os alunos público-alvo da Educação Especial, principalmente aqueles com AH/SD, após identificação apropriada.

Recomenda-se, ainda, que pesquisas com tal temática sejam realizadas em maior número e divulgadas, incentivando o trabalho com alunos com essas características para que possam ser notados, valorizados e incentivados a sempre progredirem e investirem em seus talentos, fazendo a diferença na sociedade, conforme almejado por Renzulli (2018).

\section{Conclusóes}

Trabalhos sobre os temas de AH/SD, criatividade e bilinguismo vêm sendo publicados com maior frequência nos últimos anos. No entanto, por meio da busca realizada, verificou-se que a literatura conectando os três tópicos ainda é escassa. Dentre os dez trabalhos encontrados nessa revisão, feita por meio da busca em três bases de dados a partir do cruzamento dos três termos supracitados, observou-se que a maior parte dos textos se interessava pela investigação da relação entre AH/SD e bilinguismo, discutindo-se a forma apropriada de se avaliar e trabalhar com indivíduos com essas duas características no intuito de valorizar diferenças culturais e linguísticas. Outros artigos tiveram como foco a avaliação da criatividade de pessoas bilíngues, comparando-as às monolíngues, apresentando melhores resultados em diferentes medidas de criatividade.

Outrossim, observou-se a escassez da divulgação de pesquisas empíricas, especialmente quanto às práticas para se identificar e incluir estudantes com AH/SD em ambientes bilíngues e trabalhar para o desenvolvimento de sua criatividade. Sugere-se, assim, que novas pesquisas sobre programas voltados ao trabalho com habilidades importantes ao século XXI, como criatividade e aprendizado de outros idiomas, sejam realizadas e divulgadas, especialmente tendo crianças da Educação Especial - ainda negligenciadas - como foco. 


\section{REFERÊNCIAS}

Alencar, E. M. L. S., Fleith, D. de S., Boruchovitch, E., \& Borges, C. N. (2015). Criatividade no Ensino Fundamental: fatores inibidores e facilitadores segundo gestores educacionais. Psicologia: Teoria e Pesquisa, 31(1), 105-114. https://doi.org/10.1590/0102-37722015011849105114

Aust, K., Watermann, R., \& Grube, D. (2009). Implications of ability grouping for development in general and domain-specific self-concepts of ability after the transition to Secondary Education. Zeitschrift Fur Erziehungswissenschaft, 12, 328-351.

Bahia, S. (2016). Criatividade na avaliação e intervenção na sobredotação. In F. H. R. Pisk, T., Stoltz, J. M., Machado, \& S. Bahia (Eds.), Altas habilidades/superdotação (AH/SD) e criatividade. Identificação e atendimento ( $1^{\text {a }}$ ed., pp. 145-164). Juruá.

Baser, C., \& Kanar, M. N. (2014). How can you "Gift" to Second Language Young Learners. ProcediaSocial and Behavioral Sciences, 136, 246-249. https://doi.org/10.1016/j.sbspro.2014.05.322

Biedrón, A., \& Pawlak, M. (2012). Intelligence in Gifted L2 Learners. In A. Biedrón, \& M. Pawlak (Eds.), Extending the Boundaries of Research on Second Language Learning and Teaching (1 $1^{\mathrm{a}} \mathrm{ed} ., \mathrm{pp}$. 129-242). Springer.

Biedrón, A., \& Pawlak, M. (2016). New conceptualizations of linguistic giftedness. Language Teaching, 49(2), 151-185. https://doi.org/10.1017/S0261444815000439

Brice, A. E., Shaunessy, E. S., Hughes, C. E., McHatton, P. A., \& Ratliff, M. A. (2008). What language discourse tells us about bilingual adolescents: a study of students in gifted programs and students in general education programs. Journal for the Education of the Gifted, 32(1), 7-33. https://doi. org/10.4219/jeg-2008-819

Ferreira, T. C. R. (2020). Avaliação da criatividade de alunos com e sem indicadores de Altas Habilidades/ Superdotação em ambiente bilíngue [Tese de Doutorado, Faculdade de Filosofia e Ciências, Universidade Estadual Paulista - UNESP]. Repositório da UNESP. https://repositorio.unesp.br/ handle/11449/194276

Gonçalves, F. C. (2010). Estudo comparativo entre alunos superdotados e não-superdotados em relação à criatividade, inteligência e percepção de clima de sala de aula para criatividade [Dissertação de Mestrado, Instituto de Psicologia, Universidade de Brasília - UNB]. Repositório da UNB. https:// repositorio.unb.br/handle/10482/8050

Gonzalez, V. (2006). Profiles of cognitive developmental performance in gifted children: effect of bilingualism, monolingualism, and socioeconomic status factors. Journal of Hispanic Higher Education, 5(2), 142-170. https://doi.org/10.1177/1538192705285467

Hamers, J. F., \& Blanc, M. H. A. (2004). Bilinguality and Bilingualism. Cambridge University Press.

Kitano, M. K., \& Espinosa, R. (1995). Language diversity and giftedness - working with gifted English-language learners. Journal for the education of the gifted, 18(3), 234-254. https://doi. org/10.1177/016235329501800302

Lee, H., \& Kim, K. H. (2011). Can speaking more languages enhance your creativity? Relationship between bilingualism and creative potential among Korean American students with multicultural link. Personality and Individual Differences, 50(8), 1186-1190. https://doi.org/10.1016/j. paid.2011.01.039

Leikin, M. (2012). The effect of bilingualism on creativity: Developmental and educational perspectives. International Journal of Bilingualism, 17(4), 431-447. https://doi.org/10.1177/1367006912438300 
Leikin, M., \& Tovli, E. (2014). Bilingualism and Creativity in Early Childhood. Creativity Research Journal, 26(4), 411-417. https://doi.org/10.1080/10400419.2014.961779

Mendonça, P. V. C. F., \& Fleith, D. S. (2005). Relação entre criatividade, inteligência e autoconceito em alunos monolíngües e bilíngues. Psicologia Escolar e Educacional, 9(1), 59-70. https://dx.doi. org/10.1590/S1413-85572005000100006

Nakano, T. C. (2015). Sugestóes práticas e estratégias para o desenvolvimento e treinamento de características associadas à criatividade. In M. F. Morais, L. C. de Miranda, \& S. M. Wechsler (Eds.), Criatividade: aplicaçôes práticas em contextos internacionais (1 $1^{a}$ ed., pp. 229-256). Vetor.

Palaniappan, A. K. (1994). A preliminary study of the bilingual version of Khatena-Morse Multitalent Perception Inventory. Perceptual and motor skills, 78(3), 784-786. https://doi. org/10.1177/003151259407800320

Piske, F. H. R., Stoltz, T., \& Camargo, D. (2016). A compreensão de Vigotski sobre a criança com altas habilidades/superdotação, genialidade e talento. In F. H. R. Pisk, T. Stoltz, J. M. Machado, \& S. Bahia (Eds.), Altas habilidades/superdotação (AH/SD) e criatividade. Identificação e atendimento (1 ed., pp. 207-217). Juruá.

Remoli, T. C., \& Capellini, V. L. M. F. (2017). Relação entre criatividade e altas habilidades/superdotação: uma análise crítica das produçóes de 2005 a 2015. Revista Brasileira de Educaçáo Especial, 23(3), 455-470. https://dx.doi.org/10.1590/s1413-65382317000300010

Renzulli, J. S. (2018). Reexaminando o papel da educação para superdotados e o desenvolvimento de talentos para o Século XXI: uma abordagem teórica em quatro partes. In A. Virgolim (Ed.), Altas habilidades/superdotação. Processos criativos, afetivos e desenvolvimento de potenciais ( $1^{a}$ ed., pp. 1942). Juruá.

Renzulli, J. S., \& Reis, S. M. (1997). The schoolwide enrichment model: a how-to guide for educational excellence. Creative Learning Press.

Ribeiro, O. C., \& Galvão, A. T. (2018). Expertise, criatividade e altas habilidades/superdotação: um estudo na busca de fronteiras. In A. Virgolim (Ed.), Altas habilidades/superdotaçâo. Processos criativos, afetivos e desenvolvimento de potenciais ( $1^{\text {a }}$ ed., pp. 113-139). Juruá.

Secretaria de Educação Especial \& Ministério da Educação. (2006). Saberes e Práticas da Inclusão: desenvolvendo competências para o atendimento às necessidades educacionais especiais de alunos com altas habilidades/superdotação. MEC, Secretaria de Educação Especial.

State Board of Education - State of Iowa. (2008). Identifying gifted and talented English language learners. The Connie Belin and Jacqueline N. Blank International Center for Gifted Education and Talent Development. https://educateiowa.gov/sites/files/ed/documents/IdentifyGiftedTalentedELL.pdf

Strand, S. (1998). A 'value added' analysis of the 1996 primary school performance tables. Educational Research, 40, 123-137. https://doi.org/10.1080/0013188980400201

Wei, L. (2000). The Bilingualism Reader. Routledge.

Yang, Z., Zhou, Y., Chung, J. W. Y., Tang, Q., Jiang, L., \& Wong, T. K. S. (2018). Challenge Based Learning nurtures creative thinking: An evaluative study. Nurse Education Today, 71, 40-47. https:// doi.org/10.1016/j.nedt.2018.09.004

Recebido em: 20/02/2021

Reformulado em: 25/04/2021

Aprovado em: 01/05/2021 
FERREIRA, T.C.R.; CHACON, M.C.M; CAPELLINI, V.L.M.F; 